\title{
Predictors of perioperative myocardial infarction in patients undergoing off-pump coronary artery bypass grafting
}

\author{
Mohamed A. Amr ${ }^{*}$ (1) and Elsayed Fayad
}

\begin{abstract}
Background: Perioperative myocardial infarction (PMI) increases morbidity and mortality after off-pump coronary artery bypass grafting $(C A B G)$. The objective of the current study was to characterize patients with PMI after off-pump CABG and identify its predictors.

Results: We included 1181 patients who had off-pump CABG from 2010 to 2020; 59 patients (5\%) had PMI. We compared patients with PMI to those without PMI. Patients with PMI were older (57 (25th-75th percentiles: 51-63) vs. 54 (48-60) years; $P=0.01$ ) and had higher NYHA class (28 (47.46\%) vs. $326(29.06 \%): P=0.01)$. The distal anastomosis time was longer in patients with PMI (28 (23-35) vs. 24 (16-30) min; $\left.P^{<} 0.001\right)$. Patients with PMI had higher postoperative low cardiac output (10 (18.18\%) vs. $1(0.1 \%)$ : $\left.P^{<} 0.001\right)$, prolonged ventilation $\left(12(8-39)\right.$ vs. $8(6-10) \mathrm{h}, P^{<}$ 0.001), ICU (71 (46-138) vs. 24 (23-42) h; $\left.P^{<} 0.001\right)$, and hospital stay (9 (6-15) vs. 7 (6-8) days; $\left.P^{<} 0.001\right)$. Mortality was significantly higher in patients with PMI (20 (33.9\%) vs. $\left.6(0.53 \%) ; P^{<} 0.001\right)$. Older age (OR: 1.05 (95\% Cl: $\left.1.01-1.1\right) ; P=$ 0.02), increased number of distal anastomoses (OR: 1.74 (95\% Cl: 1.20-2.50); $P=0.003$ ), preoperative congestive heart failure (OR: 10.27 (95\% Cl: 2.58-40.95); $P=0.001)$, and thrombolysis within $24 \mathrm{~h}$ of surgery (OR: $15.34(1.93-121.9) ; P=$ 0.01 ) were associated with increased PMI, while PMI was lower in male patients (OR: 0.42 (95\% Cl: 0.19-0.93); $P=0.03$ ) and with higher body surface area (BSA) (OR: 0.08 (95\% Cl: 0.07-0.86); $P=0.04)$.
\end{abstract}

Conclusions: Post-off-pump CABG PMI was associated with increased morbidity and mortality. Risk factors for PMI were older age, lower BSA, females, increased distal anastomoses, preoperative heart failure, and thrombolysis.

Keywords: Perioperative myocardial infarction, Off-pump coronary artery bypass grafting, Mortality

\section{Background}

Perioperative myocardial infarction (PMI) after coronary artery bypass grafting (CABG) is associated with high morbidity and mortality [1]. The incidence of PMI varies widely in the literature depending on the diagnostic criteria, and it ranges from 2 to $10 \%$ [2]. Several factors could contribute to the occurrence of PMI, including early graft occlusion, coronary thrombosis, poor myocardial protection, or incomplete revascularization [3].

*Correspondence: doctor2001eg@yahoo.com

Faculty of Medicine, Suez Canal University, Ismailia, Egypt
Incomplete revascularization was reported during the early experience with off-pump CABG, and it could be a risk factor for increased PMI in those patients [4]. Recently, off-pump CABG became the standard of care in several centers with comparable complete revascularization to on-pump CABG [5]. Recent studies showed no difference between on and off-pump CABG in PMI occurrence [6]. Identifying predictors of PMI in patients undergoing off-pump CABG could improve surgical outcomes. Therefore, the objectives of the current study were to characterize patients with PMI after off-pump CABG and identify its predictors. original author(s) and the source, provide a link to the Creative Commons licence, and indicate if changes were made. The images or other third party material in this article are included in the article's Creative Commons licence, unless indicated otherwise in a credit line to the material. If material is not included in the article's Creative Commons licence and your intended use is not permitted by statutory regulation or exceeds the permitted use, you will need to obtain permission directly from the copyright holder. To view a copy of this licence, visit http://creativecommons.org/licenses/by/4.0/. 


\section{Methods}

\section{Design and patients}

This retrospective study was conducted from 2010 to 2020 in a single center. The study included 1181 patients who had off-pump CABG. We included off-pump CABG patients who had primary or redo, elective, or emergency surgery. Preoperatively unstable patients on high inotropic support or intra-aortic balloon pump and those who had minimally invasive off-pump CABG were excluded. All patients had surgery through a median sternotomy. The Local Ethical Committee approved the data collection for the study, and the need for patients' consent was waived because of the retrospective design.

\section{Study data, outcomes, and definitions}

Preoperative data collected for the study included the demographics, comorbidities, and laboratory results. Operative data included the operative urgency, redo surgery, and distal anastomoses' number and time. Postoperative outcomes included low cardiac output, pulmonary complications, renal impairment, stroke, and mortality. The primary outcome was PMI, and patients were classified according to the PMI into no-PMI and PMI groups. PMI was diagnosed by the presence of at least two of these: a new $Q$ wave, CK-MB elevation, and new wall motion abnormality in echocardiography. Stroke was defined as neurological defects persisting more than $24 \mathrm{~h}$ with confirmatory computed tomography findings. Transient ischemic attacks are neurological defects that resolve within $24 \mathrm{~h}$. Ejection fractions were classified as good (> $50 \%)$, fair (30-49\%), and poor ( $^{<}$ $30 \%)$. Hospital outcomes occurred within the same hospital admission or within 30 days of the operation. The need for postoperative mechanical support defined the low cardiac output syndrome. Pulmonary complications included re-intubation, pneumothorax, or pleural effusions that required interventions. Renal impairment was defined as elevated serum creatinine more than 1.5 times the preoperative level or the need for postoperative renal replacement therapy. Infective complications included sternal wound infection and mediastinitis.

\section{Statistical analysis}

We described continuous data as mean and standard deviation if normally distributed or median and (25th75 th percentiles) if not normally distributed. We used the student $t$-test to compare normal continuous data and the Mann-Whitney test for non-normal continuous variables. We described categorical variables as frequencies and percentages and compared them with the chi-square or Fisher exact test when appropriate. Univariable logistic regression analysis was performed. Variables with a
$P$-value of 0.015 or lower in the univariable analysis were included in a multivariable model. Multivariable logistic regression analysis with backward elimination was used to identify risk factors for PMI. Variables with a $P$-value of less than 0.05 were included in the final model. Model calibration was tested using the Hosmer-Lemeshow test and discrimination using the area under the curve. All analyses were performed using Stata 16 (Stata Corp- College Station, TX, USA), and a $P$-value of less than 0.05 was considered statistically significant.

\section{Results}

Preoperative data

Fifty-nine patients (5\%) had PMI. Patients with PMI were compared to those without PMI. Patients with PMI were significantly older $(P=0.01)$, had higher New York Heart Association (NYHA) $(P=0.01)$ and Canadian Cardiovascular Society (CCS) classes $(P=0.049)$, and history of heart failure $\left(P^{<} 0.001\right)$. Hypertension was more common in patients with PMI $(P=0.04)$. There were no significant differences in other comorbidities, laboratory results, and ejection fraction (Table 1).

\section{Operative data}

There were no differences regarding the operative urgency and redo surgery between PMI and non-PMI patients. However, the distal anastomosis time was longer in patients with PMI (28 (23-35) vs. 24 (16-30) min; $P<0.001)$, and they had smaller coronary artery sizes $(P=0.01)$. The distal anastomoses were higher in PMI patients $\left(P^{<} 0.001\right)$ (Table 2$)$.

\section{Postoperative outcomes}

Patients with PMI had higher postoperative low cardiac output, blood transfusion, re-exploration for bleeding, pulmonary complications, infective complications, prolonged ventilation, ICU, and hospital stay. Mortality was significantly higher in patients with PMI $\left(P^{<} 0.001\right)$ (Table 3).

\section{Factors associated with PMI}

Multivariable logistic regression analysis revealed that older age (OR: 1.05 (95\% CI: 1.01-1.1); $P=0.02$ ), number of distal anastomoses (OR: 1.74 (95\% CI: 1.20-2.50); $P=0.003)$, preoperative congestive heart failure (OR: 10.27 (95\% CI: 2.58-40.95); $P=0.001$ ), and thrombolysis within $24 \mathrm{~h}$ of surgery (OR: 15.34 (1.93-121.9); $P=$ 0.01) were associated with increased PMI, while PMI was lower in male patients (OR: 0.42 (95\% CI: 0.19-0.93); $P=$ 0.03 ) and with higher body surface area (BSA) (OR: 0.08 (95\% CI: 0.07-0.86); $P=0.04$ ) (Table 4). 
Table 1 Comparison of the preoperative data between patients with and without perioperative myocardial infarction

\begin{tabular}{|c|c|c|c|}
\hline & Non-PMI patients $(n=1122)$ & PMI patients $(n=59)$ & $P$ \\
\hline Age (years) & $54(48-60)$ & $57(51-63)$ & 0.01 \\
\hline Male & $959(85.47 \%)$ & $45(76.27 \%)$ & 0.05 \\
\hline $\mathrm{BMI}\left(\mathrm{kg} / \mathrm{m}^{2}\right)$ & $27.8(24.8-30.9)$ & $28.2(24.2-33.2)$ & 0.62 \\
\hline $\mathrm{BSA}\left(\mathrm{m}^{2}\right)$ & $1.9(1.8-2)$ & $1.9(1.8-2)$ & 0.22 \\
\hline NYHA III-IV & $326(29.06 \%)$ & $28(47.46 \%)$ & 0.01 \\
\hline CCS III-IV & $463(41.27 \%)$ & $32(54.24 \%)$ & 0.049 \\
\hline Congestive heart failure & $17(1.52 \%)$ & $5(8.47 \%)$ & $<0.001$ \\
\hline Previous myocardial infarction & $334(29.93 \%)$ & $19(32.79 \%)$ & 0.65 \\
\hline Thrombolysis within $24 \mathrm{~h}$ & $9(0.81 \%)$ & $2(3.51 \%)$ & 0.1 \\
\hline Previous $\mathrm{PCl}$ & $112(10.02 \%)$ & $5(8.77 \%)$ & 0.76 \\
\hline Diabetes mellitus & $461(41.35 \%)$ & $31(52.54 \%)$ & 0.09 \\
\hline Hypertension & $606(54.25 \%)$ & $40(67.80 \%)$ & 0.04 \\
\hline Severe renal impairment/dialysis & $26(2.33 \%)$ & $3(5.08 \%)$ & 0.18 \\
\hline COPD & $24(2.15 \%)$ & $3(5.08 \%)$ & 0.15 \\
\hline Cerebrovascular disease & $27(2.42 \%)$ & $1(1.69 \%)$ & >0.99 \\
\hline Peripheral vascular disease & $13(1.17 \%)$ & $2(3.45 \%)$ & 0.17 \\
\hline Atrial fibrillation & $4(0.37 \%)$ & 0 & >0.99 \\
\hline Hemoglobin (mg/dl) & $13.5(12.4-14.3)$ & $13.2(12.4-14.2)$ & 0.75 \\
\hline Creatinine (mg/dl) & $1(0.9-1.2)$ & $1(0.9-1.3)$ & 0.55 \\
\hline Bilirubin (mg/dl) & $0.6(0.5-0.8)$ & $0.6(0.4-0.8)$ & 0.26 \\
\hline Ejection fraction & & & 0.11 \\
\hline Good & $846(77.54 \%)$ & $39(67.24 \%)$ & \\
\hline Fair & $234(21.45 \%)$ & $18(31.03 \%)$ & \\
\hline Poor & $11(1.01 \%)$ & $1(1.72 \%)$ & \\
\hline
\end{tabular}

Continuous variables were presented as mean and standard deviation if normally distributed and median (25th-75th percentiles) if not normally distributed. Categorical data were presented as frequencies and percentages

$B M I$ body mass index, BSA body surface area, CCS Canadian Cardiovascular Society, COPD chronic obstructive pulmonary disease, NYHA New York Heart Association, $P C l$ percutaneous coronary interventions, $P M I$ perioperative myocardial infarction

Table 2 Comparison of the operative data between patients with and without perioperative myocardial infarction

\begin{tabular}{|c|c|c|c|}
\hline & Non-PMI patients $(n=1122)$ & PMI patients $(n=59)$ & $P$ \\
\hline Urgent surgery & $6(0.53 \%)$ & $1(1.69 \%)$ & 0.30 \\
\hline Redo surgery & $23(2.05 \%)$ & $1(1.69 \%)$ & >0.99 \\
\hline Number of distal anastomoses & & & $<0.001$ \\
\hline 1 & $484(43.14 \%)$ & $9(15.25 \%)$ & \\
\hline 2 & $376(33.51 \%)$ & $21(35.59 \%)$ & \\
\hline 3 & 205 (18.27\%) & $23(38.98 \%)$ & \\
\hline 4 & $56(4.99 \%)$ & $5(8.47 \%)$ & \\
\hline 5 & $1(0.09 \%)$ & $1(1.69 \%)$ & \\
\hline Coronary size (mm) & $1.6 \pm 0.74$ & $1.5 \pm 0.30$ & 0.01 \\
\hline Total distal anastomosis time (min) & $24(16-30)$ & $28(23-35)$ & $<0.001$ \\
\hline
\end{tabular}

Continuous variables were presented as mean and standard deviation if normally distributed and median (25th-75th percentiles) if not normally distributed. Categorical data were presented as frequencies and percentages

$P M I$ perioperative myocardial infarction

\section{Discussion}

Perioperative myocardial infarction after coronary artery bypass grafting still presents a major cause of morbidity and mortality [7]. Our study found that PMI patients had higher postoperative complications, including low cardiac output, pulmonary and renal complications, prolonged 
Table 3 Comparison of the postoperative outcomes between patients with and without perioperative myocardial infarction

\begin{tabular}{llll}
\hline & Non-PMI patients $(\boldsymbol{n}=\mathbf{1 1 2 2})$ & PMI patients $(\boldsymbol{n}=\mathbf{5 9 )}$ & $\boldsymbol{P}$ \\
\hline Low cardiac output & $1(0.10 \%)$ & $10(18.18 \%)$ & $<7(88.68 \%)$ \\
Blood transfusion & $632(61.54 \%)$ & $11(20.75 \%)$ & $<.001$ \\
Re-exploration & $30(2.92 \%)$ & $12(8-39)$ & $<.001$ \\
Duration of mechanical vent (h) & $8(6-10)$ & $12(24 \%)$ & $<.001$ \\
Pulmonary complications & $16(1.56 \%)$ & $2(4 \%)$ & $<.001$ \\
Stroke & $2(0.20 \%)$ & $5(9.80 \%)$ & 0.001 \\
Infective complications & $11(1.07 \%)$ & $9(18 \%)$ & 0.01 \\
New onset renal impairment & $22(2.15 \%)$ & $11.1(10.1-11.9)$ & 0.001 \\
Hemoglobin on discharge $(\mathrm{mg} / \mathrm{dl})$ & $11.7(11-12.5)$ & $1(0.9-1.3)$ & 0.001 \\
Creatinine on discharge $(\mathrm{mg} / \mathrm{dl})$ & $1(0.9-1.2)$ & $0.6(0.4-1)$ & 0.04 \\
Bilirubin on discharge $(\mathrm{mg} / \mathrm{dl})$ & $0.7(0.5-1)$ & $73(46-138)$ & 0.41 \\
ICU stay (h) & $24(23-42)$ & $9(6-15)$ & 0.27 \\
Hospital stay (days) & $7(6-8)$ & $20(33.90 \%)$ & $<.001$ \\
Mortality & $6(0.53 \%)$ & 0.001 \\
\hline
\end{tabular}

Continuous variables were presented as mean and standard deviation if normally distributed and median (25th-75th percentiles) if not normally distributed. Categorical data were presented as frequencies and percentages

ICU intensive care unit, $P M I$ perioperative myocardial infarction

Table 4 Risk factors for perioperative myocardial infarction

\begin{tabular}{lll}
\hline & $\begin{array}{l}\text { Odds ratio (95\% } \\
\text { confidence interval) }\end{array}$ & $P$ \\
\hline Males & $0.42(0.19-0.93)$ & 0.03 \\
Age & $1.05(1.01-1.1)$ & 0.02 \\
Body surface area & $0.08(0.07-0.86)$ & 0.04 \\
Number of distal anastomoses & $1.74(1.20-2.50)$ & 0.003 \\
Congestive heart failure & $10.27(2.58-40.95)$ & 0.001 \\
Thrombolysis within 24h & $15.34(1.93-121.9)$ & 0.01 \\
\hline
\end{tabular}

Area under the curve $=0.76$; goodness of fit $P=0.75$

mechanical ventilation, ICU, and hospital stay. Additionally, PMI was associated with higher mortality. We identified risk factors for PMI in our cohort and included older age, female gender, low BSA, congestive heart failure, thrombolysis, and a higher number of distal anastomoses.

The incidence of PMI varies widely in the literature. A major cause for this variability is the different diagnostic criteria and techniques used [8]. According to several reports, no optimal single diagnostic criteria for PMI are available, and combined diagnostic approaches are recommended [9]. The debate between on-pump and off-pump CABG continues, and the practice varies in different centers. In a meta-analysis of studies comparing on-pump and off-pump CABG, no difference in myocardial injury was reported between groups [10].

Hospital and long-term sequelae risk could be improved if the risk factors are identified and properly managed. Several risk factors associated with PMI after off-pump CABG were reported. The presence of collaterals could protect the patients against PMI [11]. We found that the risk of PMI was associated with increasing the number of distal anastomoses. This finding is similar to what was reported by Nathoe and colleagues [12]. This observation could be attributed to the longer distal occlusion time, leading to PMI in patients with poor collaterals. Therefore, several strategies could be used to reduce distal ischemia or improve the collateral circulation, such as the use of intra-coronary shunts [13], coronary staplers [14], or ischemic preconditioning [15]. Alkhouli and colleagues found that females, heart failure, dialysis, cirrhosis, emergency $C A B G$, and mechanical circulatory support predicted early PMI after CABG [16]. In our series, congestive heart failure and recent thrombolysis increased the risk of PMI. These factors indicated patients' instability with severe coronary artery disease. CABG in patients with cardiogenic shock or those who failed non-surgical revascularization was associated with high morbidity and mortality [17]. In other series, the female gender was a risk factor for PMI, which was related to the smaller coronary arteries and poor collaterals [18]. We confirmed this finding in our patients, and we found that females had a higher risk of PMI. Similarly, lower BSA was associated with PMI, which could be related to the coronary artery sizes.

PMI was associated with increased complications and mortality in our series. Patients with PMI had prolonged ventilation, ICU, and hospital stay. Another study reported a negative impact of PMI on hospital outcomes, while there was no difference in long-term outcomes [19]. However, other studies showed that PMI negatively affected the incidence of longterm cardiovascular outcomes after CABG [20]. 


\section{Study limitations}

The study is limited by the retrospective design; however, PMI is a rare event, and this is the optimal study design to evaluate risk factors for PMI. Additionally, the study is a single-center experience, and several factors could be related to the operating surgeons and their expertise. Several unmeasured variables could have affected the outcomes and were not included in the analysis. Finally, we did not include invasive measures to diagnose PMI.

\section{Conclusions}

Post-off-pump CABG PMI was associated with high morbidity and mortality. Older age, lower BSA, females, increased distal anastomoses, preoperative heart failure, and thrombolysis were related to increased PMI. Targeting these factors could improve the outcomes of surgery.

\section{Abbreviations}

BSA: Body surface area; CABG: Coronary artery bypass grafting; CCS: Canadian Cardiovascular Society classes; COPD: Chronic obstructive pulmonary disease; ICU: Intensive care unit; NYHA: New York Heart Association; OPCAB: Off-pump coronary artery bypass grafting; PMI: Perioperative myocardial infarction.

\section{Acknowledgements}

Not applicable.

\section{Authors' contributions}

Mohamed amr: conceived and designed the analysis, collected the data, data analysis and took part in writing the paper. Elsayed Fayad: data collection and took part in writing the paper. The authors read and approved the final manuscript.

\section{Funding}

No funding was received for this project. This research did not receive any grants from funding agencies in the public, commercial, or non-profit sectors.

\section{Availability of data and materials}

The authors declare that the data supporting the findings of this study are available upon request.

\section{Declarations}

Ethics approval and consent to participate

Consent to participate was waived by the Ethical Committee.

\section{Consent for publication}

Not applicable

\section{Competing interests}

The authors declare that there is no conflict of interest. Additionally, the authors have no financial interest or ties in or with the product or product distributor.

Received: 19 December 2021 Accepted: 28 December 2021

Published online: 03 January 2022

\section{References}

1. Vanden Eynden F, Cartier R, Marcheix B, Demers P, Bouchard D (2009) Prognosis of perioperative myocardial infarction after off-pump coronary artery bypass surgery. J Cardiovasc Surg 50(4):535-543

2. Davierwala PM, Verevkin A, Leontyev S, Misfeld M, Borger MA, Mohr FW (2013) Impact of expeditious management of perioperative myocardial ischemia in patients undergoing isolated coronary artery bypass surgery. Circulation. 128(11 Suppl 1):S226-S234

3. Sef D, Szavits-Nossan J, Predrijevac M, Golubic R, Sipic T, Stambuk K et al (2019) Management of perioperative myocardial ischaemia after isolated coronary artery bypass graft surgery. Open Hear 6(1):e001027 Available from: http://openheart.bmj.com/content/6/1/e001027.abstract

4. Benedetto U, Caputo M, Patel NN, Fiorentino F, Bryan A, Angelini GD (2017) Long-term survival after off-pump versus on-pump coronary artery bypass graft surgery. Does completeness of revascularization play a role? Int J Cardiol 246:32-36

5. Puskas JD, Williams WH, Duke PG, Staples JR, Glas KE, Marshall JJ et al (2003) Off-pump coronary artery bypass grafting provides complete revascularization with reduced myocardial injury, transfusion requirements, and length of stay: a prospective randomized comparison of two hundred unselected patients undergoing off-pump versus c. J Thorac Cardiovasc Surg 125(4):797-808

6. Bakaeen FG, Chu D, Kelly RF, Holman WL, Jessen ME, Ward HB (2014) Perioperative outcomes after on- and off-pump coronary artery bypass grafting. Texas Hear Inst J 41(2):144-151

7. Ben-Yehuda O, Chen S, Redfors B, McAndrew T, Crowley A, Kosmidou l et al (2019) Impact of large periprocedural myocardial infarction on mortality after percutaneous coronary intervention and coronary artery bypass grafting for left main disease: an analysis from the EXCEL trial. Eur Heart J 40(24):1930-1941

8. Lim CCS, Cuculi F, van Gaal WJ, Testa L, Arnold JR, Karamitsos T et al (2011) Early diagnosis of perioperative myocardial infarction after coronary bypass grafting: a study using biomarkers and cardiac magnetic resonance imaging. Ann Thorac Surg 92(6):2046-2053

9. Weidenmann V, Robinson NB, Rong LQ, Hameed I, Naik A, Morsi M et al (2020) Diagnostic dilemma of perioperative myocardial infarction after coronary artery bypass grafting: a review. Int J Surg 79:76-83

10. Shaefi S, Mittel A, Loberman D, Ramakrishna H (2019) Off-pump versus on-pump coronary artery bypass grafting-a systematic review and analysis of clinical outcomes. J Cardiothorac Vasc Anesth 33(1):232-244

11. Eriksen UH, Nielsen TT, Egeblad H, Bagger JP (2002 Jul) Coronary collaterals during single-vessel coronary angioplasty: effects of nitroglycerin. Clin Cardiol 25(7):340-344

12. Nathoe HM, Moons KGM, van Dijk D, Jansen EWL, Borst C, de Jaegere PPT et al (2006) Risk and determinants of myocardial injury during off-pump coronary artery bypass grafting. Am J Cardiol 97(10):1482-1486

13. Vallely MP, Ross DE (2010) Intracoronary shunts and off-pump surgery. Ann Thorac Surg 90:700-701 author reply 701

14. Balkhy HH, Nisivaco SM, Husain AN, Jeevanandam V, Arif Q (2018) The C-port distal coronary anastomotic device is comparable with a hand-sewn anastomosis: human histological case study. Innovations (Phila) 13(2):140-143

15. Hausenloy DJ, Candilio L, Evans R, Ariti C, Jenkins DP, Kolvekar S et al (2015) Remote ischemic preconditioning and outcomes of cardiac surgery. N Engl J Med 373(15):1408-1417

16. Alkhouli M, Alqahtani F, Alreshidan M, Cook CC (2019) Incidence, predictors, and outcomes of early acute myocardial infarction following coronary artery bypass grafting. Am J Cardiol 124(7):1027-1030

17. Ibrahim M, Spelde AE, Gutsche JT, Cevasco M, Bermudez CA, Desai ND et al (2021) Coronary artery bypass grafting in cardiogenic shock: decision-making, management options, and outcomes. J Cardiothorac Vasc Anesth 35(7):2144-2154

18. O'Connor GT, Morton JR, Diehl MJ, Olmstead EM, Coffin LH, Levy DG et al (1993) Differences between men and women in hospital mortality associated with coronary artery bypass graft surgery. The northern New England cardiovascular disease study group. Circulation. 88(5 Pt 1):2104-2110

19. Järvinen $\mathrm{O}$, Hokkanen $M$, Huhtala $H$ (2014) The long-term effect of perioperative myocardial infarction on health-related quality-of-life after coronary artery bypass grafting. Interact Cardiovasc Thorac Surg 18(5):568-573

20. Riedel BJ, Grattan A, Martin CB, Gal J, Shaw AD, Royston D (2006) Longterm outcome of patients with perioperative myocardial infarction as diagnosed by troponin I after routine surgical coronary artery revascularization. J Cardiothorac Vasc Anesth 20(6):781-787

\section{Publisher's Note}

Springer Nature remains neutral with regard to jurisdictional claims in published maps and institutional affiliations. 